\title{
Senior Management Perspectives of Mathematics and Statistics Support in higher education: Moving to an 'Ecological' Approach
}

\author{
By Helen Mackenzie ${ }^{1}$, Harry Tolley ${ }^{1}$, Tony Croft $^{2}$, Michael Grove ${ }^{3} \&$ Duncan \\ Lawson $^{4}$ \\ ${ }^{1}$ Researchers for the sigma Network, Mathematics Education Centre, Loughborough \\ University, Loughborough, LE11 3TU, UK. \\ ${ }^{2}$ Mathematics Education Centre, Loughborough University, Loughborough, LE11 \\ 3TU, UK. \\ ${ }^{3}$ School of Mathematics, University of Birmingham, Birmingham, B15 2TT, UK \\ (m.j.grove@bham.ac.uk). \\ ${ }^{4}$ Newman University, Birmingham, B32 3NT, UK.
}

\begin{abstract}
This article explores the perspectives of three senior managers in higher education institutions in England regarding their mathematics and statistics support provision. It does so by means of a qualitative case study that draws upon the writing of Ronald Barnett about the identity of an 'ecological' university, along with metaphors associated with the notion of organisations as living 'organisms', suggested by Gareth Morgan. Using these ideas as a heuristic sheds light upon the view that whilst outwardly universities appear to represent a uniform landscape, mathematics and statistics support alternatively, can be seen as different 'species' within the higher education system. The study illustrates how three universities occupying contrasting ecological 'niches' are responding to the challenges they face by providing and planning different forms of learning support for mathematics and statistics. In conclusion, it is recommended that senior managers reflect upon the possibilities offered by the idea of 'ecological' identities in order to explore how they might respond strategically to a rapidly changing environment. This includes adapting various solutions and the further development of innovative ways of supporting students' transitions throughout the academic lifecycle. In addition, an ecological approach could also aid the formation of the co-creational relationships and networks required for the future success of those developments.
\end{abstract}

Keywords: Management; higher education; ecological university; student transition; mathematics and statistics support.

\section{Introduction}

This article builds upon research into the strategic needs of the higher education sector in England with regard to mathematics and statistics support, including the assistance institutions might require from the Higher Education Funding Council for England (HEFCE) and the sigma Network (Tolley \& Mackenzie, 2015). This support has developed significantly over two decades, responding to challenges faced by students as they enter, and progress through their university education and on into employment (Hawkes \& Savage, 2000; Advisory Committee on Mathematical Education (ACME), 2011; Durrani \& Tariq, 2012; British Academy, 2015). The predominant mode of delivery has become the support centre, a facility within which students can access learning resources and one-to-one guidance from tutors. As such, provision has grown (Perkin, Croft \& Lawson, 2013) and a community of 
practitioners has developed collectively forming the sigma Network and working to promote, develop and embed excellence in mathematics and statistics support within higher education. In 2013 HEFCE funded the sigma Network to develop and embed its work throughout the English higher education sector (Croft et al., 2015).

For the purposes of the research upon which this article draws, interviews were conducted with senior managers (typically pro-vice-chancellors) from 23 universities in which the following strategic issues were discussed:

- Challenges faced by students in relation to mathematics and statistics.

- How those challenges were being addressed.

- The degree to which support was embedded and visible.

- Plans and intentions with regard to future provision and how those institutional priorities were determined.

- The external support universities continue to need.

Thematic induction was used to identify, code, and categorise the data (Braun \& Clarke, 2006). Ethical guidelines by the British Educational Research Association (BERA, 2011) were followed to preserve confidentiality and anonymity. This article outlines three illustrative cases (Stake, 1995) to highlight the challenges universities face, how institutions are responding, and, their future vision with regard to mathematics and statistics support.

\section{Theoretical context: the changing higher education system in an age of 'supercomplexity'}

Higher education in England is currently in a period of rapid change (see: Barnett, 2011; Callender \& Scott, 2013; Scott, 2015; and, Department for Business and Skills, 2015) where government-led initiatives have resulted in a shift from an elite to a mass system of tertiary education, league tables, and marketisation. Within this transformed system increased importance is attached to students' recruitment, retention, achievement and employability (Department for Business, Innovation and Skills, 2011 ; 2015). This period of rapid change has also been accompanied by enhanced challenges, risk and uncertainty and aligns with what Barnett (2000a; 2000b) describes as being not just complex, but 'supercomplex'.

Many of the criticisms relating to these changes have centred on the marketisation of higher education. Whilst there is a differentiated system (Scott, 2015) made up of research-intensive universities, regional universities that focus more on teaching, specialists institutions and private providers of professional training, outwardly there is a perceived lack of diversity across the sector. For example in league tables all universities are judged by the same criteria, and the majority have set their fees at, or close to $£ 9000$ per year (Wyness, 2013). According to Scott (2015) there is a sense that a uniform landscape exists within which the academic identity, associated with it becoming increasingly entrepreneurial, corporate and bureaucratic (Barnett, 2011). However, the idea of an entrepreneurial university alone, has been viewed as inadequate to face the challenges associated with a supercomplex age rather, it has been suggested that other 'feasible utopias' (Barnett, 2011) need to be considered. Those possibilities include the need for universities to become more liquid, authentic and therapeutic (Barnett, 2011) and ultimately, shift to working in more creative and imaginative ways in order to build collaborative connections within universities as 
well as with local, regional, national and global communities. Barnett (2011) describes the essence of this vision of the university as being 'ecological' evoking the idea that it resides within a system that operates in both space and time. As such the university is authentic in advancing its own particular interests with regard to teaching and research, whilst being responsible towards both the inner higher education system and the wider outer world.

Barnett's ideas have similarities with those expressed by Morgan (1986), who argued that by 'using different metaphors to understand the complex and paradoxical character of organisational life, we are able to manage and design organisations in ways we may not have thought possible before' (Morgan, 1986, p.13). He went on to suggest that when the 'organisms' metaphor is applied to organisations it enables us to think of them as:

[L]iving systems, existing in a wider environment on which they depend for satisfaction of various needs' and that 'as we look around the organisational world we begin to see that it is possible to identify different species of organisation in different kinds of environment. (Morgan, 1986, p.39)

It is argued here that when these notions are adopted as a heuristic, they enable us to view the management and provision of mathematics and statistics support afresh.

\section{Research Design}

For the purposes of this article a collective (Stake, 1995) case study approach is adopted, with the focus upon a carefully selected sample. A case study is distinctive because it is treated as a bounded system. In this study, the cases were defined as being bound firstly by the focal point of the enquiry, which is an exploration concerning mathematics and statistics support. The cases are also bounded by time, because the data collection took place over a period of two months (April-May 2014) and also, by place - they are higher education institutions situated at different locations in England. Finally, the cases are bound by the type of institution they represent in terms of what the Universities and Colleges Admissions Service (UCAS, 2014) refer to as 'high tariff', 'medium tariff' and 'low tariff' providers, a classification of universities based upon the average level of attainment of applicants they accept. Overall the cases were chosen because they illustrate different perspectives, and were identified as being instrumental (Stake, 1995) in increasing our understanding about what the different challenges, provision and future needs are in relation to mathematics and statistics support within the higher education sector.

Three cases, representing different higher education institutions, were determined by purposeful sampling (Creswell, 1998) through secondary analysis of the original data. The analysis revealed that whilst all higher education institutions in the sample had areas of divergence and manage their mathematics and statistics support differently there was also convergence, particularly at the lower end and higher end of each tariff range. The three case studies therefore, were selected from the top of the high-band, middle of the medium-band and bottom of the low-band because both, within case and cross-case analysis (Creswell, 1998) revealed the greatest contrast between each of the cases. Universities within England, upon which this work is based, all undertake research, teaching and knowledge transfer activities, although the balance of these activities varies and as such so does their overall mission focus: some 
institutions concentrate primarily on teaching whereas others are more research intensive. A number of universities have formed groups with common interests, these include regional university associations and also so-called 'mission groups'. For example, the 'Russell Group' is an association of 24 major research-intensive universities of the United Kingdom. Other 'mission groups' include, for example, million+ - an association for modern universities, and University Alliance - a group formed of universities based in cities and regions; some universities remain unaligned to any of these groups. Case studies are drawn from universities within these different mission groups in order to be as representative as possible.

This study does not claim that the empirical findings are generalisable in the same way as those derived from quantitative or scientific research; rather it is aligned with the alternative approach developed by Stake (1995) and Stake and Trumbull (1982) called naturalistic generalisation. This involves knowledge about the cases being transferred from the researcher to the reader through a descriptive narrative. It is the reader therefore, who decides if the findings from one study can be applied to similar situations.

\section{The Case Studies}

Drawing upon the suggestion by Morgan (1986) that a population perspective aids the understanding of the dynamics that influence the ecology of organisations, a detailed description of each case is provided in the following format:

- An introduction providing contextual information.

- The challenges faced in relation to mathematics and statistics.

- Responses to those challenges and the university's visions of future developments.

The cases are each given a title offering an indication of the ecological 'niche' they occupy.

\section{Case Study 1: A 'Regional' University}

This is a 'low tariff' provider offering a place for students of all ages to study with a high proportion of its intake coming from low-income households in the local region. It aims to provide high quality teaching and is seeking to develop its research in ways that will benefit society, industry and business. It has strong links with local colleges and higher education institutions in the region, and is seeking to grow national and international collaborations. It is a member of one of the university 'mission groups' and the sigma Network.

The challenges it faces with regard to mathematics and statistics are related to the transitions its students make into and within higher education (including their progression to postgraduate study) and into employment. Many have achieved no higher than the minimum entrance requirement of a General Certificate of Secondary Education (GCSE) Grade C in mathematics leaving them with knowledge gaps, and lacking confidence in the subject. (GCSEs are public examinations taken in various subjects at the age of 16.) Whilst many of its mature students have mathematics qualifications, it is often the case that they have not studied or applied the subject for some time, thus needing learning support. To compound the situation many of the 
teaching staff also have difficulties with mathematics and statistics, and play down their importance with students opting to study their subjects. Finally, employment numeracy tests are an obstacle to its graduates when seeking to enter the labour market.

In response, an overarching strategy has been developed for improving student retention, academic achievement and employability, which complements the outreach and widening participation initiatives set out in its Access Agreement. Within England, the Office for Fair Access (OFFA), the independent public body that regulates fair access to higher education in England, requires all universities to produce a publicly available document (an Access Agreement) that details its specific approaches and activities for widening participation in higher education from traditionally underrepresented groups of learners. Support for academic learning, including that targeted on mathematics and statistics, is a key priority for the university under the leadership of a deputy vice-chancellor. Specific initiatives with regard to mathematics and statistics include curriculum development work on core modules of subjects in which students are known to struggle with the embedded mathematics and/or statistics. A mathematics and statistics support centre is located in a dedicated learning space on the main campus. It provides face-to-face mathematics and statistics support for students from across the university on a drop-in basis, and workshops for those preparing for graduate numeracy tests. Its role includes both outreach and public engagement. A study skills team makes available learning support to individual students, and specialists from the team support academic colleagues in their work with students. The mathematics and statistics support centre works closely with the university's 'Guidance and Employability' and 'Wellbeing' teams.

In the short-term there are plans to extend learning support for mathematics and statistics as part of a university-wide strategy for enhancing the student experience. To that end, the mathematics and statistics support centre will provide workshops for programme leaders, and promote discussion of a range of topics including the implications for higher education of curriculum and examination change postcompulsory education (for example Advanced-level (A-level) and AdvancedSupplementary (AS) qualifications typically taken between the ages of 16 and 18). It will continue to engage with the sigma Network with a view to learning from the experiences of other mathematics and statistics support centres. In particular, it will be seeking guidance on enhancing the learning and achievements of students who have been 'turned off' by their prior experiences of mathematics at school and/or college. It would also welcome opportunities to access continuing professional development for its staff aimed at enabling them to embed innovative methods into the design and delivery of their courses with a view to making the experience of learning mathematics and statistics more effective for their students. Finally, at a national level it would welcome development initiatives aimed at improving the mathematical and statistical understanding of applicants before they arrive at university.

\section{Case Study 2: A 'National' University}

This is a large multi-campus university - over 80 per cent of its students being undergraduates, and over 90 per cent of its students being UK residents. It is a UCAS 'medium level tariff provider', which has achieved a high (top 20) position in league 
tables for teaching quality and many of its research centres are judged to be doing 'world class' research. It is a member of a 'mission group' and other national and international higher education organisations, and has strong vocational links with the arts, business, industry, science and professional bodies. It has no formal involvement with the sigma Network.

Challenges occur at three levels of mathematics and statistics, according to discipline including, high-level (e.g. science, technology, engineering and mathematics (STEM)), medium-level (e.g. economics, social sciences and health), and low-level (e.g. creative arts and humanities) where little or no numeracy is required. Upon entry many students have not studied any form of mathematics (or statistics) as part of their post-16 education. As a result of this 'time lapse', students have difficulties reengaging with the subject(s). Many students also enter with only GCSE Grade C in mathematics, serious knowledge gaps and a lack of confidence in their ability making studying alongside students with A-level mathematics qualifications in some teaching groups problematic. In addition, over 2000 students have been diagnosed as dyslexic (many with specific learning difficulties relating to number) with some students experiencing high levels of anxiety in relation to mathematics. Final year social science undergraduates and some postgraduate students experience difficulties when undertaking research projects using quantitative methods. As in Case 1, occupational numeracy tests are also an obstacle to some graduates when seeking employment.

Many forms of support for mathematics and statistics are being implemented as part of a wider strategy aimed at improving students' retention, achievement and employability. Because of the wide range of undergraduate courses, support differs according to the programme being studied, for example across STEM it is embedded in core modules. In other subjects, additional classes are available to students in relation to certain modules (e.g. those in which quantitative methods are being introduced), and the staff provide tutorials for those who need/request them. In some subjects this is complemented by 'peer mentoring' supported by online resources, pod-casts, web-casts, and practice tests. In one of the faculties students can access support on a drop-in basis at a new mathematics and statistics support centre. Use of that centre is being piloted with a view to making it available to students from across the university. Finally, support is available to students via a 'maths café' modelled on an earlier initiative aimed at improving students' academic literacy.

Mathematics and statistics support is integral to strategies that encompass other forms of learning such as writing, and build on experiences from earlier initiatives. In its most recent Access Agreement developments aimed at improving student retention and achievement are linked to the university's outreach and widening participation activities and enhancing students' employability. There is also a commitment to developing and evaluating online resources. This will allow support to be extended to students before they enter the university. The university is also seeking ways of making more effective use of students' course level profile data so that lecturers know in advance, for example, how many students in a group have A-level, AS-level, GCSE or alternative qualifications in mathematics, the aim being 'to work with the students the university has, rather than the ones it thinks it has'. The intention is that decision-making will be made within the framework of the university's strategic planning for enhancing the curriculum, and will be driven by the analysis of data on 
student satisfaction, retention, achievement, and employability, thus enabling interventions to be more precisely targeted and effectively implemented.

\section{Case Study 3: An 'International' University}

This is a UCAS 'high level tariff provider' at which over 90 per cent of its students are full-time, two thirds are international students, and almost 50 per cent are postgraduates. It is research intensive and undertakes 'world-class research' across all faculties. It is highly ranked in national and international league tables for the quality of both its teaching and research. As a 'global' university it has many international higher education partners in relation to both research and teaching. It is and a member of a university 'mission group' but has no formal involvement with the sigma Network.

The challenges the university faces relate to the transitions made by its students into and within higher education (including their progression to Year 3 of their undergraduate courses), to postgraduate study, and to employment. Despite the fact that the majority of its students have achieved A/A* grades at AS/A-level in a number of subjects they are not necessarily well prepared for higher education courses that require them to study mathematics and/or statistics. Some students who do not have a post-GCSE qualification and/or lack confidence in mathematics avoid engaging with the mathematical/statistical aspects of their subjects (e.g. through their choice of modules), which causes problems in Year 3 when they have to write dissertations and engage with literature that draws on quantitative research. Its graduates have to be able to demonstrate competence in mathematics/statistics in order to progress to postgraduate study or research and/or enter highly competitive national and international graduate labour markets. The university has to manage the tensions around requiring its students to engage with mathematics and statistics and maintaining high levels of student satisfaction. Its academics are heavily committed to their research resulting in pressures when seeking to provide the staffing needed to consistently deliver high quality teaching including learning support for mathematics and statistics.

A pro-vice-chancellor exercises a strategic oversight of matters relating to teaching and learning including provision of support for mathematics and statistics, and the university's widening participation, outreach and fair access strategy. Support for mathematics and statistics is embedded at critical points within the undergraduate curriculum (e.g. in Year 1 core modules) with teaching inputs by staff from the Mathematics Department working in collaboration with subject specialists. Mathematics and statistics support is also available on demand to students by means of a 'drop-in' facility. That support is well established and highly visible - though there are no references to it in the university's OFFA Access Agreement, and there is no indication as to how it might be linked to outreach and widening participation.

The provision of support for mathematics and statistics is being reviewed across the university, though it is accepted that it will need to be on-going if students are to make successful transitions into and within higher education and on to employment. Consideration is being given to the possibility of developing foundation courses (as part of a 1 plus 3 undergraduate degree structure) that would include modules on mathematics, statistics, academic writing, critical thinking and research methods. This would enable current widening participation and fair access initiatives to be further developed and linked with student achievement and employability, and made explicit 
in the university's OFFA Access Agreement. Currently 'home-grown' solutions are being developed to address the challenges its students face in relation to mathematics and statistics. Nevertheless it is recognised that much could be learned from the experiences of other higher education institutions and the sigma Network. The latter being seen as the 'first port of call' for guidance in terms of resources and access to continuing professional development for its staff. However, the university is conscious of working in a highly competitive environment and takes the view that any partnership arrangements with other higher education institutions will need to be 'carefully managed'.

\section{Discussion}

The three cases illustrate how contrasting universities in England are managing mathematics and statistics support provision. Using ideas set out previously as a heuristic, it is proposed that each case represents different 'species' set within distinct environments (Morgan, 1986) or, 'niches' within the wider higher education ecological system. As a result, the cases are adapting, planning, providing and viewing their support in a variety of ways, at different paces, in response to their perception of the challenges they face.

In each case those challenges are multifaceted and relate to the notion of students in transition (see e.g., Grove, Croft, Kyle \& Lawson, 2015; Mackenzie, 2011) into and within higher education, and out into employment, in what could be termed the 'student life cycle'. Issues were identified around students' mathematical experiences prior to entering university and the changing 'outer' environment. These range from students who have not studied any form of mathematics post-16 (resulting, for example, in knowledge 'gaps' and a lack of confidence) to the teaching of classes with a mix of different qualifications in mathematics, through to those with high grades at A-level who still have learning difficulties. The negative attitudes of some students towards studying mathematics or statistics can also raise tensions around student satisfaction surveys, as highlighted by Case 3 .

As indicated above, the heterogeneous nature of the student population within the 'inner' university environment raises challenges. These are not confined to mathematical sciences and the STEM disciplines, but extend to wherever quantitative methods are used - a concern raised by Case 1 and 2. In addition, Case 2 noted difficulties around supporting students with disabilities and specific differences in their learning of mathematics and statistics. Overall, the universities are under pressure to produce graduates with the numerical skills needed to compete successfully in the labour market, and progress to postgraduate courses, which are often more quantitative than their undergraduate counterparts. This is exacerbated by tensions associated with some staff finding it difficult to engage with mathematics and statistics, and the challenge of delivering high quality teaching and learning support provision when staff (like those in Case 3) are heavily committed to research.

These challenges are unlikely to decrease in the near future as indicated by the Organisation for Economic Co-operation and Development (Kuczera, Field, \& Windisch, 2016), which reported that English teenagers (aged 16-19) have only a basic grasp of mathematics and are ranked $22^{\text {nd }}$ of the 23 developed nations surveyed. In addition, the Advisory Committee for Mathematics Education (ACME, 2015) suggested that it would take a decade for reforms to the curriculum and assessment 
system (e.g. the introduction of 'Core Maths') to be effective. Hence the challenges to higher education posed by mathematics and statistics will continue into the foreseeable future. Furthermore, adoption of the concept of an ecological university in order to better understand the challenges and manage the associated responses suggests that a therapeutic (Barnett, 2011) strategy is perhaps the most appropriate. Such an approach includes sensitivity to, and care for, the wellbeing of students and the development of their skills in mathematics and statistics within both the 'inner' and wider 'outer' ecology. This requires consideration of the authenticity (Barnett, 2011) of the university, to prompt reflection around the ecological 'niche' it presently occupies and action around the 'species' it is and might plan to become.

In response to the above challenges it appears that each of the cases is already taking an ecological approach towards the management of its mathematics and statistics support and in so doing is adapting to, and evolving within its own ecological 'niche'. As such, provision varies between cases, ranging from a focus on targeted support that is restricted in scope and embedded within the curriculum alongside a 'drop in' facility (Case 3), to support embedded in the curriculum along with other initiatives including peer mentoring, online resources, a 'maths cafe' and a pilot mathematics and statistics support centre (Case 2), to a more comprehensive support system (Case 1). Thus the size and networking system of the supportive environment provided within their 'niches', is different. For example, the co-creational connections with the 'outer' environment in Case 1 show a commitment to developing an overarching strategy for improving student retention, achievement and employability, which complements its outreach and widening participation initiatives. Thus, Case 1 has established co-creational relationships and networks pointing to symbiotic, relationships between the university and the outreach and public engagement activities it undertakes, resulting in beneficial impact and wellbeing within its 'outer' and 'inner' ecology. In contrast, Case 3 is managing responses that are narrower in scope involving 'home grown' solutions. However, it plans to develop widening participation and fair access initiatives and to extend support provision. As Morgan (1986) suggested, organisations (like organisms) are not entities living in discrete isolation - they exist as elements within complex ecosystems.

The rate or 'fluidity' (Barnett, 2011, p.11) of change also varies with Cases 1 and 3 already having in place established support systems, while Case 2 is still in the process of developing and extending support across the disciplines to all its undergraduate students. Indeed, the rate of change varied across the original sample indicating that additional 'species' to those discussed here exist within different ecological 'niches' across the higher education system.

In practice, the student experience lies at the centre of the response of the three cases in their attempts to changes in their 'outer' environments. In this context, Temple, Callender, Grove, and Kersh (2014) showed that in a small number of cases externally driven reforms have resulted in changes in organisational structures, policies, and processes, with research-intensive universities responding differently from others in the sample. In general, the latter were found to be centralising student services, standardising procedures and strengthening senior management controls, and in so doing reducing decision-making at departmental level. Research-intensive universities on the other hand, were encouraging a greater concern for the students' experience without engaging in comprehensive organisational change. A report to the 
Department for Business, Innovation and Skills (2014) from OFFA and HEFCE however, set out a strategy for combining fair access to higher education with student success, which would address the following issues across the student lifecycle: fair access; retention; academic achievement; and, progression to further study and/or employment. Whilst the focus is on combining fair access and success for students from disadvantaged backgrounds, the report also expressed the view that the adoption of a broader, lifecycle approach would benefit all students attending the full spectrum of higher education providers. It would seem therefore, that the provision of mathematics and statistics support should now be seen in a wider context that includes consideration of matters such as outreach, recruitment, the student experience and employability and hence, connect and co-create within the wider 'ecological' higher education system.

All three cases indicate that they need to continue to adapt and develop in order to improve the effectiveness of the support they offer within their own ecological 'niche'. This includes creating, extending and strengthening networks. Whilst Case 1 is the only university to have a formal involvement with sigma, it emerged that Case 3 respected the knowledge the sigma Network has acquired about mathematics and statistics support. Guidance for developing resources and provision of continuing professional development were identified as areas needing on-going assistance. Case 1 indicated that it would welcome assistance from sigma with regard to the dissemination of good practice in mathematics and statistics support centres along with access to continuing professional development for its academic staff. This suggests that the cases are not simply adapting to the environment, but are exploring networks with others and seeking ways to creatively re-construct it. Case 3 however, indicated that working with other universities within the same 'niche' would have to be 'managed carefully' suggesting that competition is a barrier, or that a 'survival of the fittest' is an approach to be adopted.

The need for further work to address the challenges posed around the student life cycle were also identified. In particular, further creative innovations focused upon students making the transition into university, were highlighted. This includes discussions around the possible development of foundation courses (Case 3), the use of online resources and students' course level profile data (Case 2) and a call for national initiatives aimed at improving the mathematical and statistical understanding of applicants before they arrive at university (Case 1). This indicates that the development of mathematics and statistics support provision in the future cannot be done in isolation, but must be part of wider strategic considerations including outreach, fair access and student: recruitment; retention; achievement; and employability. Thus transformational changes required for mathematics and statistics support is becoming to be acknowledged as part of a university-wide, 'ecological' system of support. Hence, there is a need for further research that focuses upon an indepth examination of a small number of higher education institutions to gain a greater understanding about the leadership, strategic thinking, brokerage and engagement with staff and students by which different forms of mathematics and statistics support were developed. Further, the networks, connections and key individuals and management processes that have provided the leadership and guidance for these processes also merits more detailed study. It is anticipated that future work could lead to the development of guidance targeted at senior managers and those responsible for the management and implementation of mathematics and statistics support. 


\section{Conclusion}

It is anticipated that this case study will help readers to identify with aspects of mathematics and statistics support with which they are familiar and view the management and provision of it, from a new perspective. By adopting the idea of the 'ecological university' and organisations as 'organisms' as a heuristic, it is hoped that senior managers might be prompted to think afresh about the management of mathematics and statistics support. This includes not only issues around change, adaptation and development, but also consideration about the environment that universities inhabit and their relationships, networks (including sigma), and cocreation with the other relevant organisms or 'species' and the wider 'outer' world. Whilst there is a range of 'species' that exists within the 'supercomplex' environment of the higher education 'ecological' system, it is possible that species can learn from each other and adapt solutions better suited to their individual identities.

\section{Acknowledgements}

The authors would like to express their appreciation and thanks to all senior members of staff and their personal assistants from each of the higher education institutions that took part in this research.

\section{References}

Advisory Committee on Mathematical Education (ACME). (2011). Mathematics in the workplace and in higher education. London: Royal Society.

Advisory Committee on Mathematical Education (ACME). (2015). Beginning teaching: best in class? High quality initial teacher education for all teachers of mathematics in England. London: Royal Society.

Barnett, R. (2000a). University Knowledge in an Age of Supercomplexity. Higher Education, 40(4), 409-422.

Barnett, R. (2000b). Realising the University in an Age of Supercomplexity. Buckingham: Open University Press.

Barnett, R. (2011). Being a University. London and New York: Routledge.

Braun, V. and Clarke, V. (2006). Using thematic analysis in psychology. Qualitative Research in Psychology, 3, 77-101. doi: 10.1191/1478088706qp063oa

British Academy. (2015). Count us in: Quantitative Skills for a New Generation. London: The British Academy.

British Educational Research Association (BERA) (2011). Ethical Guidelines for Educational Research. [Online] Retrieved from https://www.bera.ac.uk/wpcontent/uploads/2014/02/BERA-Ethical-Guidelines-2011.pdf.

Callender, C. and Scott, P. (2013). Browne and Beyond: Modernizing English higher education. London: Institute of Education Press: Bedford Way Papers.

Creswell, J.W. (1998). Qualitative Inquiry And Research Design: Choosing Among 
Five Traditions. Thousand Oaks, California: SAGE Publications.

Croft, A.C., Lawson, D.A., Hawkes, T.O., Grove, M.J., Bowers, D. and Petrie, M. (2015). sigma - a network working! Mathematics Today, 50(1).

Department for Business, Innovation and Skills (2011). Students at the Heart of the System. London: Department for Business Innovations and Skills.

Department for Business, Innovation and Skills (2014). National Strategy for Access and Student Success in higher education. London: Department for Business Innovations and Skills.

Department for Business, Innovation and Skills (2015). Fulfilling our Potential:

Teaching Excellence, Social Mobility and Student Choice. London: Department for Business Innovations and Skills.

Durrani, N. and Tariq, V.N. (2012). The role of numeracy skills in graduate employability. Education and Training, 54(5) 419-434.

doi:10.1108/00400911211244704

Grove, M., Croft, T., Kyle, J. and Lawson, D. (eds) (2014). Transitions in Undergraduate Mathematics Education. Birmingham: The University of Birmingham.

Hawkes, T. and Savage, M. (2000). Measuring the Mathematics Problem. London: Engineering Council.

Kuczera, M., Field, S. and Windisch, H, C. (2016). Building Skills for All: A Review of England. Policy Insights from the Survey of Adult Skills. OECD Skills Studies: OECD.

Mackenzie. H, E. (2011). Students' experiences of academic play within transitional space in higher education. Unpublished PhD. University of Nottingham. Retrieved from http://eprints.nottingham.ac.uk/id/eprint/13449/1/546540.pdf.

Morgan, G. (1986). Nature Intervenes: Organizations as Organisms. In Images of Organization (1986). London: Sage Publications Ltd, 19-38.

Perkin, G., Croft, A, C., and Lawson, D, A. (2013). The extent of mathematics learning support in UK higher education-the 2012 survey. Teaching Mathematics and Its Applications, 32(4) 165-172. doi: 10.1093/teamat/hrt014

Scott, P. (2015). 'There is a Third Way Universities Could Take Between State and Market'. The Guardian 7 July, 2015 Retrieved from

http://www.theguardian.com/education/2015/jul/07/universities-build-networks-worktogether.

Stake, R.E. and Trumbull, D.J. (1982). Naturalistic Generalizations. [Online] Retrieved from education.illinois.edu/circe/publication/naturalistic.pdf. 
Stake, R. E. (1995). The Art of Case Study Research. California: SAGE.

Temple, P., Callender, C., Grove, L., and Kersh, N. (2014). Managing the student experience in a shifting higher education landscape. York: The higher education Academy.

Tolley, H. and Mackenzie, H.E. (2015). Establishing Senior Management Perspectives on Learning Support for Mathematics and Statistics in the higher education Sector in England. Loughborough: Loughborough University.

UCAS (2014). End of Cycle Report (2014): UCAS Analysis and Research. Cheltenham: UCAS.

Wyness, G. (2013). As Easy as ABB: The Impact of the Quasi-market on Institutions, Student Numbers and the higher education Sector. In Callender, C. and Scott, P. (eds) (2013) Browne and Beyond: Modernizing English higher education. London. IOE Press 89-111. 